СТАТЬИ

УДК 633.4:632.51

ВЛИЯНИЕ ПРЕДШЕСТВЕННИКОВ НА ЗАСОРЕННОСТЬ ПОСЕВОВ КОРНЕПЛОДОВ ПРИ ПРИМЕНЕНИИ ОРГАНИЧЕСКОЙ ТЕХНОЛОГИИ

\author{
Анохина О.В., Егушова Е.А., Старикова Д.Е., Ульрих Е.В. \\ ФГБОУ ВО «Кузбасская государственная сельскохозяйственная академия», \\ Кемерово, e-mail: agriculture@ksai.ru
}

Севооборот является одним из главных факторов, определяющих фитосанитарное состояние посевов, относясь к числу наиболее эффективных и экологически безопасных методов защиты, так как способствует конкурентоспособности различных культур. В полевом опыте изучено влияние различных предшественников на засорённость посевов и урожайность корнеплодов. Объектами исследования служили сорт моркови Самсон и гибрид свёклы Боро F1. Корнеплоды высевались по двум предшественникам - яровая пшеница и картофель. В посевах корнеплодов выявлено 9 видов сорных растений из 7 семейств. В агроценозе преобладали малолетние сорняки: горец почечуйный (Polygonum persicaria L.), щирица запрокинутая (Amaranthus retroflexus L.), лебеда раскидистая (Atriplex patula L.), щетинник сизый (Setaria glauca L.), пастушья сумка (Capsella bursa-pastoris L.), просо куриное (Echinochloa crus-galli L.), составлявшие 76,9-97,1\% от общего количества в посевах моркови и 80,0-97,1\% в посевах свёклы. Из многолетних сорняков встречались: пырей ползучий (Elytrigia répens L.), осот полевой (Sonchus arvensis L.) и вьюнок полевой (Convolvulus arvensis L.). Наименьшее количество сорняков было выявлено при размещении по картофелю: в период смыкания рядков засоренность моркови не превышала 7 шт./м² по картофелю и 14 шт./м² - по яровой пшенице. В посевах свеклы также наименьшая засоренность отмечена по пропашному предшественнику - 5 шт./м², по яровой пшенице насчитывалось 11 шт./м² сорняков. Урожайность корнеплодов, размещенных по предшественнику картофель, была максимальной и составила у свёклы 31,4 т/га, у моркови - 32,4 т/га.

Ключевые слова: засорённость, предшественник, урожайность, корнеплоды, органическая технология, севооборот

\title{
THE IMPACT OF FORECROPS ON THE CONTENT OF IMPURITIES OF ROOT CROPS USING ORGANIC TECHNOLOGY
}

\author{
Anokhina O.V., Egushova E.A., Starikova D.Ye., Ulrikh E.V. \\ Kuzbass State Agricultural Academy, Kemerovo, e-mail: agriculture@ksai.ru
}

\begin{abstract}
Crop rotation is one of the main factors that determine the phytosanitary state of crops, being one of the most effective and environmentally friendly methods of protection, as it contributes to the competitiveness of various crops. The impact of various precursors on content of impurities and root crops yielding capacity has been studied in the field experience. The objects of the study were the Samson carrot variety and the Boro F1 beet hybrid. Root crops were sown according to two predecessors - spring wheat and potatoes. In the crops of root crops, 9 species of weeds from 7 families were identified. In the agrocenosis, juvenile weeds prevailed: Polygonum persicaria (L.), Amaranthus retroflexus (L.), Atriplex patula (L.), Setaria glauca (L.), Capsella bursa-pastoris (L.), Echinochloa crus-galli (L.), which accounted for 76.9-97.1\% of the total amount in carrot crops and 80.0-97.1\% in crops beets. Of the perennial weeds, there were: Elytrígia répens (L.), Sonchus arvensis (L.) and Convolvulus arvensis (L.). The smallest amount of weeds were found when placed on potatoes: during the row closure period, carrot infestation did not exceed $7 \mathrm{pcs} / \mathrm{m}^{2}$ for potatoes and $14 \mathrm{pcs} / \mathrm{m}^{2}$ for spring wheat. In beet crops, the least infestation was also recorded for cultivated forecrops $-5 \mathrm{pcs} / \mathrm{m}^{2}$ and $11 \mathrm{pcs} / \mathrm{m}^{2}$ for spring wheat. The yielding capacity of root crops of the potato precursor was the highest, $31.4 \mathrm{t} /$ ha of beets and $32.4 \mathrm{t} / \mathrm{ha}$ of carrots.
\end{abstract}

Keywords: content of impurities, forecrop, yielding capacity, root crops, organic technology, crop rotation

Правильный выбор предшествующей культуры является одним из резервов повышения урожайности. Севооборот - важное средство восстановления и повышения почвенного плодородия. Он регулирует процессы накопления и разложения органического вещества, минерализации гумуса, а также увеличивается продуктивность севооборота за счёт эффективного использования последействия одних видов культур на последующие [1].

При строгом соблюдении научно обоснованных севооборотов и рациональном использовании системы удобрений можно избежать истощения запасов основных элементов минерального питания и поддерживать содержание их в пахотном слое на уровне средней и высокой обеспеченности [2].

В органические севообороты для повышения почвенного плодородия рекомендуют вносить зелёные удобрения. При включении в севооборот сидеральных культур засорённость на порядок ниже, чем при внесении органических удобрений. Так, при посеве сидератов (клевер луговой) в почве семян сорняков было на 65 \% ниже, чем в севообороте только с однолетними яровыми зерновыми культурами. Снижение засорённости в полях севооборота, где высевались сидеральные культуры, наблюдали ещё в течение трёх лет [3]. 
Севооборот является одним из главных факторов, определяющих фитосанитарное состояние посевов, относясь к числу наиболее эффективных и экологически безопасных методов защиты, так как способствует конкурентоспособности различных культур $[4 ; 5]$.

В технологии органического производства исключены технологические операции применения синтезированных препаратов. Восполнение питательных веществ, необходимых для роста растений, возможно за счет использования органических удобрений и агротехнических приемов, способствующих улучшению питания растений. Для широкого внедрения органического земледелия производителям необходима агротехнология, адаптированная к местным условиям [6].

Цель исследования: изучить влияние предшественников на засорённость и урожайность корнеплодов при применении органической технологии.

\section{Материалы и методы исследования}

Полевые опыты проводили в 2020 г. в КФХ «Башмаков С.А.» Прокопьевского района Кемеровской области, почва опытного участка - чернозем оподзоленный среднемощный среднегумусный среднесуглинистый, с содержанием гумуса в пахотном слое $6,7 \%$, обменного калия 130 мг/кг, подвижного фосфора 147 мг/кг почвы, $\mathrm{pH}_{\text {сол }}-6,2$.

Посев моркови проведён 3 мая, свёклы 15 мая. Повторность опыта четырёхкрат-

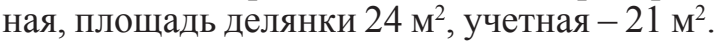
Посев проводили с шириной междурядий 70 см, норма высева моркови - 4 кг/га, свёклы - 10 кг/га, семена моркови высевали на глубину 1-2 см, свёклы - 3-4 см. В опыте использовались сорт моркови Самсон и гибрид свёклы столовой Боро F1. Корнеплоды высевались по двум предшественникам яровая пшеница и картофель.

Обработка почвы общепринятая для зоны: после картофеля осенью проводили вспашку на глубину 23-25 см. Весной при достижении физической спелости почвы - ранневесеннее боронование и предпосевная культивация перед посевом свёклы. После яровой пшеницы осенью проведена культивация на глубину 10-12 см. Весной ранневесеннее боронование и предпосевная культивация перед посевом свёклы. В 2018 г. под картофель осенью было внесено 35 т/га органических удобрений.

Уход за растениями включал довсходовое и два послевсходовых рыхления меж- дурядий, прополку. В период вегетации корнеплодов проводили фенологические наблюдения, засорённость посевов определяли в два периода вегетации корнеплодов: всходы и смыкание рядков.

Урожайность корнеплодов учитывали отдельно по повторениям и сортировали на товарные и нетоварные корнеплоды. Нетоварные корнеплоды взвешивали отдельно от товарных. При уборке по каждому повторению нетоварные корнеплоды сортировали на мелкие, искривленные, пораженные вредителями (морковная муха), разветвленные и треснутые. Далее вычисляли среднюю массу корнеплодов и процент товарного урожая. Товарные корнеплоды взвешивали и находили средний вес одного корнеплода [7].

\section{Результаты исследования и их обсуждение}

Метеорологические условия в год проведения исследований были близки к среднемноголетним показателям, наблюдался небольшой избыток влаги в июле и первой половине августа, осадков выпало выше нормы на $15 \%$ и $30 \%$ соответственно (рис. 1). Температура была выше нормы на $3,7^{\circ} \mathrm{C}$ в мае и на $2,5^{\circ} \mathrm{C}$ в августе, остальные месяцы были близки к средним многолетним показателям. В целом условия увлажнения за вегетационный период 2020 г. были благоприятными для роста и развития корнеплодов, ГТК составил 1, 2.

Обязательное условие для получения положительных результатов на культуре моркови - чистое от сорняков поле перед появлением всходов культуры. Это важно для предотвращения остановки в росте моркови в начале развития [8].

При возделывании свёклы в органическом севообороте необходимо учитывать особенности культуры. Свёкла хорошо использует последействие органических удобрений, вносимых под предшественники, поэтому рекомендуется размещать её посевы во втором и третьем поле севооборота [6].

Ввиду слабой конкурентоспособности корнеплодов к сорнякам необходимо содержать посевы чистыми от сорных растений вплоть до уборки урожая. Известно, что при высокой культуре земледелия картофель оставляет после себя поле рыхлым и чистым от сорняков, поэтому является хорошим предшественником для овощных культур [9]. 

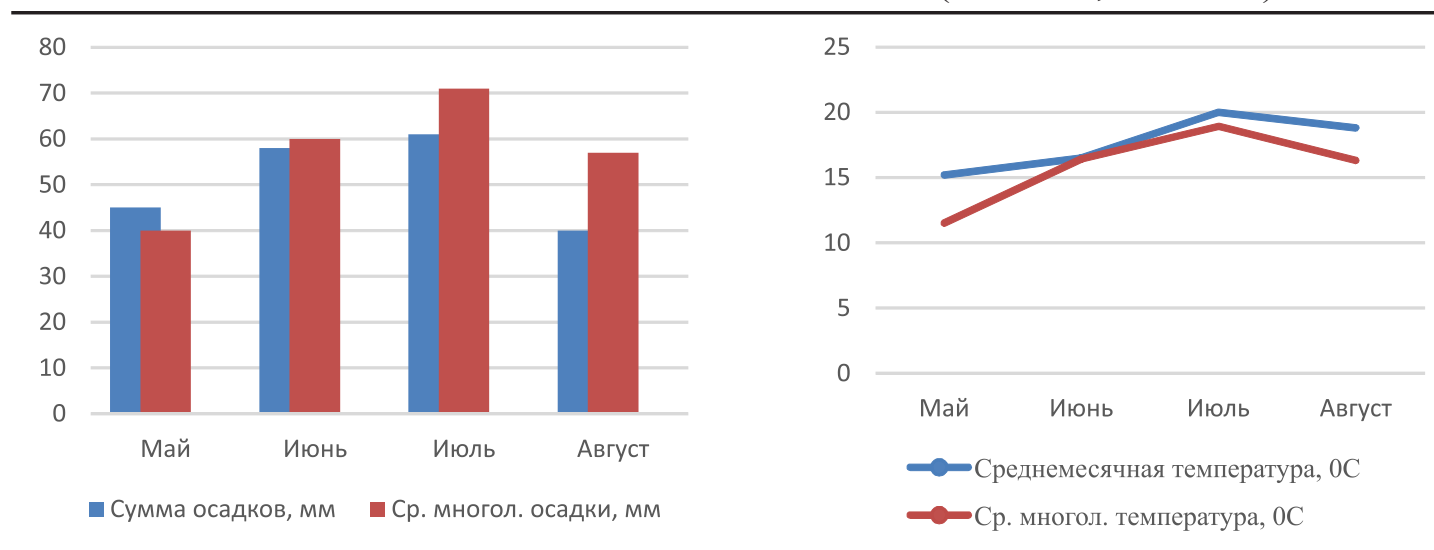

Рис. 1. Метеорологические условия вегетационного периода, 2020 г.

Флористический состав сорняков в посевах моркови и свеклы

Таблица 1

\begin{tabular}{|c|c|c|c|}
\hline Вид сорняка & Латинское название & Семейство & Биологическая группа \\
\hline \multicolumn{4}{|c|}{ Малолетние } \\
\hline Горец почечуйный & Polygonum persicaria $\mathrm{L}$. & Гречишные & Яровой ранний \\
\hline Лебеда раскидистая & Atriplex patula L. & Маревые & Яровой ранний \\
\hline Щирица запрокинутая & Amaranthus retroflexus L. & Щирицевые & Яровой поздний \\
\hline Щетинник сизый & Setaria glauca L. & Мятликовые & Яровой поздний \\
\hline Просо куриное & Echinochloa crusgalli L. & Мятликовые & Яровой поздний \\
\hline Пастушья сумка & Capsella bursa-pastoris L. & Крестоцветные & Зимующий \\
\hline \multicolumn{4}{|c|}{ Многолетние } \\
\hline Пырей ползучий & Elytrigia repens L. & Мятликовые & Корневищный \\
\hline Осот полевой & Sonchus arvensis L & Сложноцветные & Корнеотпрысковый \\
\hline Вьюнок полевой & Convolvulus arvensis L. & Вьюнковые & Корнеотпрысковый \\
\hline
\end{tabular}

За вегетационный период 2020 г. в посевах моркови и свеклы выявлено 9 видов сорных растений из 7 семейств (табл. 1). В агроценозе преобладали малолетние сорняки: горец почечуйный (Polygonum persicaria L.), щирица запрокинутая (Amaranthus retroflexus L.), лебеда раскидистая (Atriplex patula L.), щетинник сизый (Setaria glauca L.), пастушья сумка (Capsella bursa-pastoris L.), просо куриное (Echinochloa crus-galli L.), составлявшие $76,9-97,1 \%$ от общего количества в посевах моркови и $80,0-97,1 \%$ в посевах свёклы. Из многолетних сорняков встречались: пырей ползучий (Elytrígia répens L.), осот полевой (Sonchus arvensis L.) и вьюнок полевой (Convolvulus arvensis L.).

Массовые всходы малолетних сорных растений обычно появляются одновременно с всходами корнеплодов. В посевах моркови и свеклы из малолетних доминировали сорняки из семейства мятликовые (Роасеае).
Их плотность достигала в посевах моркови по предшественнику картофель 25 шт./ $\mathrm{M}^{2}$, по яровой пшенице 14 шт./M² (рис. 2). В посевах свеклы численность сорняков варьировала от 20 шт./ $\mathrm{M}^{2}$ - предшественник картофель, до 12 шт./м² по зерновому предшественнику.

Многолетние сорняки представлены двумя биологическими группами - корнеотпрысковые и корневищные. По предшественнику картофель отмечено по одному сорняку в посевах моркови и свеклы. По предшественнику яровая пшеница в посевах моркови выявлено 6 шт./м² многолетних сорных растений, в посевах свеклы - 5 шт./M², преобладал вьюнок полевой (рис. 3).

В фазу всходов на посевах моркови насчитывалось всего 35 шт./ $\mathrm{M}^{2}$ сорняков (по картофелю) и 26 шт./Mㄹ (по яровой пшенице). В посевах свеклы численность сорняков составила 29 шт./ $\mathrm{M}^{2}$ по пропашному предшественнику и 20 шт./ $\mathrm{M}^{2}$ по зерновому предшественнику (табл. 2). 


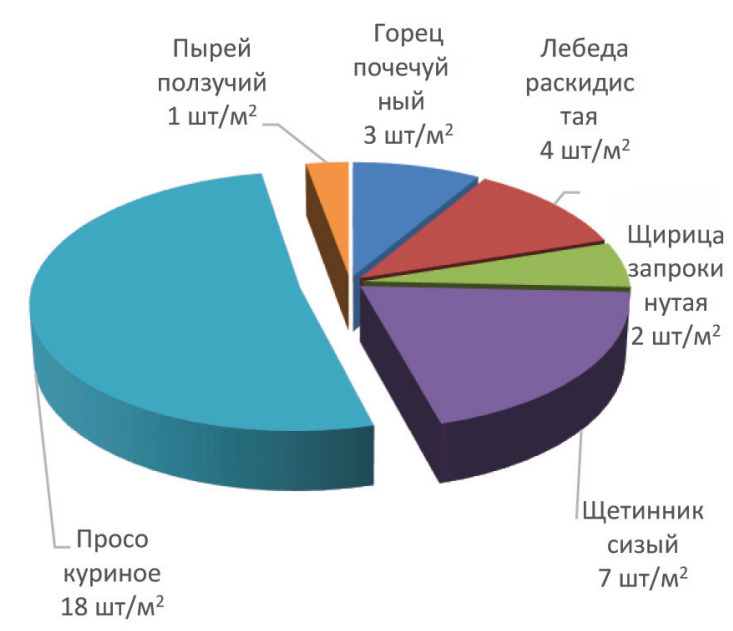

a)

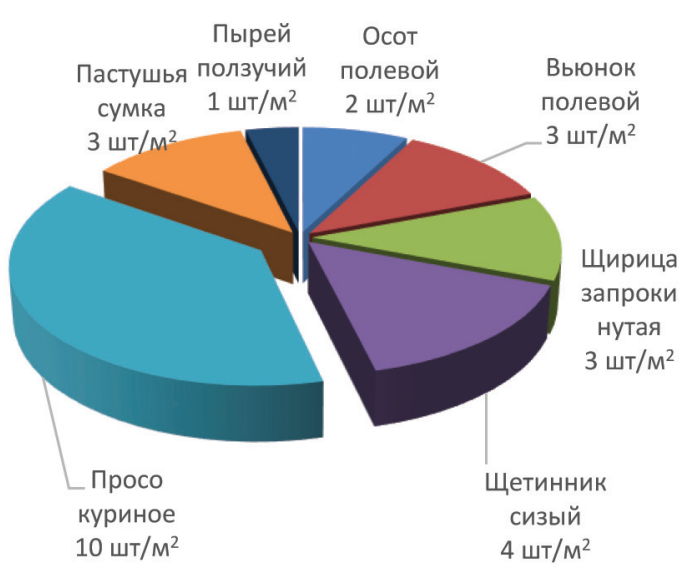

б)

Рис. 2. Численность сорняков в посевах моркови по предшественнику картофель (а) и яровая пшеница (б)

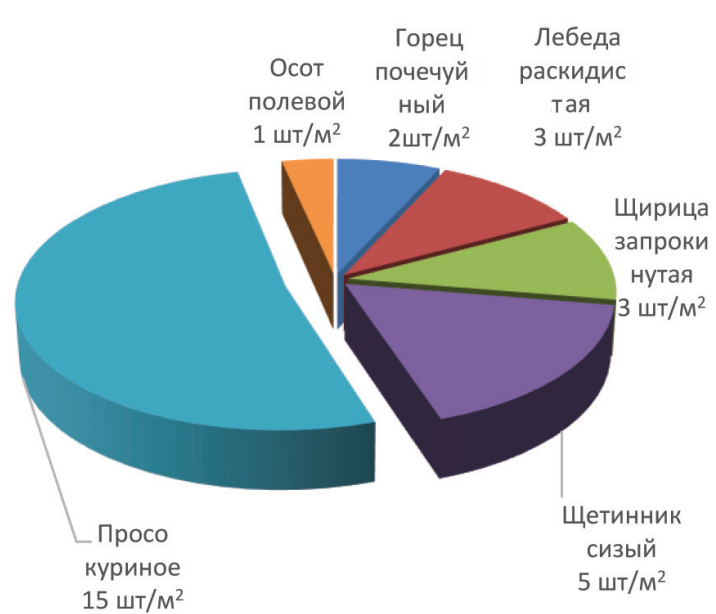

a)

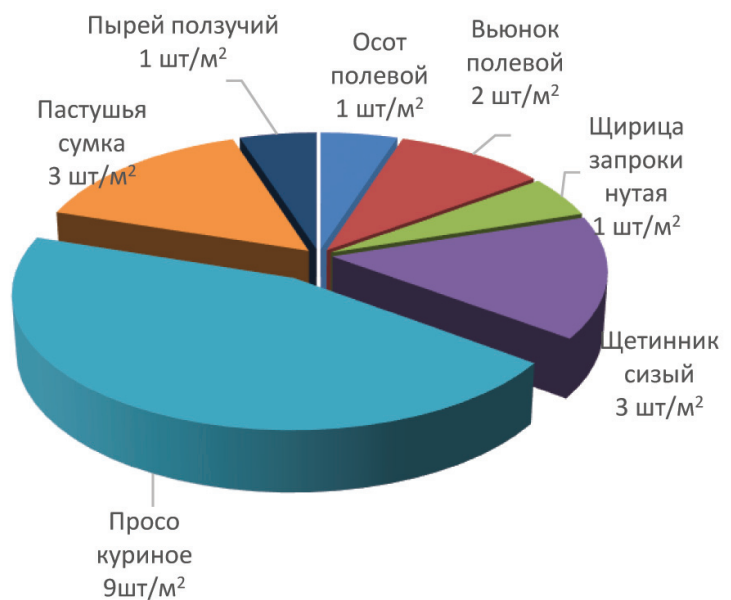

б)

Рис. 3. Численность сорняков в посевах свёкль по предшественнику картофель (а) и яровая пшеница (б)

Таблица 2

Влияние предшественников на численность сорняков в посевах корнеплодов, шт./ $\mathrm{M}^{2}$

\begin{tabular}{|c|c|c|c|c|c|c|}
\hline \multirow[t]{2}{*}{ Предшественник } & \multicolumn{3}{|c|}{ Фаза всходов } & \multicolumn{3}{|c|}{ Фаза созревания } \\
\hline & 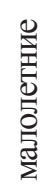 & 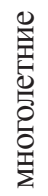 & 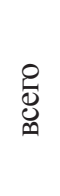 & 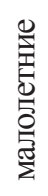 & 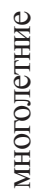 & $\underset{\mathscr{e}}{\stackrel{\mathscr{D}}{0}}$ \\
\hline \multicolumn{7}{|c|}{ Самсон } \\
\hline Картофель & 34 & 1 & 35 & 7 & - & 7 \\
\hline Яровая пшеница & 20 & 6 & 26 & 10 & 4 & 14 \\
\hline \multicolumn{7}{|c|}{ Боро F1 } \\
\hline Картофель & 28 & 1 & 29 & 5 & - & 5 \\
\hline Яровая пшеница & 16 & 4 & 20 & 8 & 3 & 11 \\
\hline
\end{tabular}


Ко времени уборки урожая засоренность моркови не превышала 7 шт./ м $^{2}$ по картофелю и 14 шт./ м $^{2}$ по яровой пшенице. В посевах свеклы также наименьшая засоренность отмечена по пропашному предшественнику -5 шт./м², по яровой пшенице насчитывалось к уборке сорняков 11 шт./M².

Урожайность и товарность корнеплодов представлены в табл. 3. У моркови сорта Самсон урожайность максимально получена по предшественнику картофель - 32,4 т/га, но выход товарной продукции был низким - 54,3\%. Выход товарных корнеплодов был выше по зерновому предшественнику $-85,5 \%$.

Влияние предшественников на урожайность корнеплодов, т/га

\begin{tabular}{|c|c|c|c|}
\hline \multirow[t]{2}{*}{ Сорт } & \multicolumn{2}{|c|}{ Урожайность, т/га } & \multirow{2}{*}{$\begin{array}{c}\text { Выход товарной } \\
\text { продукции, \% }\end{array}$} \\
\hline & общая & товарная & \\
\hline \multicolumn{4}{|c|}{ Предшественник - картофель } \\
\hline Самсон & 32,4 & 17,6 & 54,3 \\
\hline Боро F1 & 31,4 & 24,3 & 77,4 \\
\hline \multicolumn{4}{|c|}{ Предшественник - яровая пшеница } \\
\hline Самсон & 20,0 & 17,1 & 85,5 \\
\hline Боро F1 & 11,1 & 7,1 & 64,0 \\
\hline
\end{tabular}

Урожайность гибрида свёклы столовой Боро F1 значительно отличалась по предшественникам. По предшественнику картофель урожайность составила 31,4 т/га, размещение по зерновому предшественнику привело к формированию низкой урожайности 11,1 т/га, и выход товарной продукции составил $64,0 \%$.

\section{Выводы}

1. За вегетационный период 2020 г. в посевах корнеплодов выявлено 9 видов сорных растений из 7 семейств. В агроценозе преобладали малолетние сорняки: горец почечуйный (Polygonum persicaria L.), щирица запрокинутая (Amaranthus retroflexus L.), лебеда раскидистая (Atriplex patula L.), щетинник сизый (Setaria glauca L.), пастушья сумка (Capsella bursa-pastoris L.), просо куриное (Echinochloa crus-galli L.), составлявшие 76,9-97,1\% от общего количества в посевах моркови и 80,0-97,1\% в посевах свёклы. Из многолетних сорняков встречались: пырей ползучий (Elytrígia répens L.), осот полевой (Sonchus arvensis L.) и вьюнок полевой (Convolvulus arvensis L.).
2. Ко времени уборки урожая засоренность моркови не превышала 7 шт./ $\mathrm{M}^{2}$ по картофелю и 14 шт./M² - по яровой пшенице. В посевах свеклы также наименьшая засоренность отмечена по пропашному предшественнику - 5 шт./ $\mathrm{M}^{2}$, по яровой пшенице насчитывалось к уборке сорняков 11 шт./M².

3. По результатам 2020 г. при применении органической технологии в КФХ «Башмаков С.А.» Прокопьевского района можно рекомендовать для выращивания по предшественнику картофель гибрид свёклы столовой Боро F1 и сорт моркови Самсон, сформировавшие урожайность 31,4 т/га и 32,4 т/га соответственно.

\section{Список литературы / References}

1. Скорочкин Ю.П. Сахарная свёкла и севооборот // Сахарная свёкла. 2008. № 9. С. 21-22.

Skorochkin Yu.P. Sugar beet and crop // Sakharnaya svokla. 2008. No. 9. P. 21-22 (in Russian).

2. Баршадская С.И., Квашин А.А., Дерека Ф.И. Плодородие чернозема обыкновенного и продуктивность основных сельскохозяйственных культур // Плодородие. 2011. № 2. C. 36-39. DOI: 10.1016/j.agee.2020.107078.

Barshadskaya S.I., Kvashin A.A., Dereka F.I. Fertility of ordinary chernozem and productivity of main agricultural crops // Plodorodie. 2011. No. 2. P. 36-39. DOI: 10.1016/j. agee.2020.107078 (in Russian).

3. Melander B., Rasmussen I., Olesen J. Legacy effects of leguminous green manure crops on the weed seed bank in organic crop rotations. Agriculture, Ecosystems \& Environment. 2020. Vol. 302. DOI: 10.1016/j.agee.2020.107078.

4. Фетюхин И.В. Адаптивная технология возделывания сахарной свеклы в нетрадиционных районах свеклосеяния: автореф. дис. ... докт. с.-х. наук. Рассвет, 2003. 50 с.

Fetyukhin I.V. Adaptive technology of sugar beet cultivation in non-traditional areas of beet growing: avtoref. dis. ... dokt. s.-kh. nauk. Rassvet, 2003. 50 p. (in Russian).

5. Жеряков Е.В. Влияние различных предшественников на содержание органического вещества в черноземе выщелоченном и продуктивность сахарной свеклы // Аграрный научный журнал. 2015. № 2. С. 6-9.

Zheryakov E.V. The influence of various predecessors on the organic substance content In leached chernozem and productivity of sugar beet // Agrarnyy nauchnyy zhurnal. 2015. No. 2 . Р. 6-9 (in Russian).

6. Романовский Н.В. Возделывание столовой свёклы в органическом севообороте // Технология и технические средства механизированного производства продукции растениеводства и животноводства. 2017. № 93. С. 48-53.

Romanovsky N.V. Cultivation of table beet in organic crop rotation // Tekhnologiya i tekhnicheskiye sredstva mekhanizirovannogo proizvodstva produktsii rasteniyevodstva i zhivotnovodstva. 2017. No. 93. P. 48-53 (in Russian).

7. Методика государственного сортоиспытания сельскохозяйственных культур. Картофель, овощные и бахчевые культуры. М.: Колос. Вып. 4. 1975. 182 с.

Methods of state variety testing of agricultural crops. Potatoes, vegetables and melons. M.: Kolos. Vyp 4. 1975. 82 p. (in Russian).

8. Немирова Н.А., Порсев И.Н., Балуева Н.П. Интенсивная фитосанитарная технология возделывания моркови столовой в ЗАО «Картофель» Курганской области // Вестник Курганской ГСХА. 2017. № 2. С. 59-64.

Nemirova N. A., Porsev I.N., Balueva N.P. Intensive phytosanitary technology of table carrots cultivation In cjsc «kartofel» of the Kurgan region // Vestnik Kurganskoy GSKHA. 2017. of the Kurgan region // Vestni
No. 2. P. 59-64 (in Russian).

9. Крашенинник Н.В. Технологическая схема выращивания моркови // Вестник овощевода. 2010. № 1. С. 16-17.

Krasheninnik N.In. Technological scheme of growing carrots // Vestnik ovoshchevoda. 2010. No. 1. P. 16-17 (in Russian). 